\title{
EVOLUÇÃO TECTÔNICA DA MARGEM EQUATORIAL BRASILEIRA
}

\author{
PETER SZATMARI*, JOÃO BATISTA L. FRANÇOLIN**, \\ OSMAR ZANOTTO* e SVEN WOLFF***
}

\begin{abstract}
Rifting and tectonic evolution along the Equatorial margin of Brazil were highly complex. In offshore Amapá, an early stage of rifting started in Permo-Triassic time, accompanied by diabase intrusions. Volcanic activity extended eastward to the Maranhão Basin, without leading to continental breakup. In early Cretaceous time (144-119 Ma) the clockwise rotation of South America relative to Africa, about a pole situated near $39^{\circ} \mathrm{W}$ and $7^{\circ} \mathrm{S}$, caused compression west of Fortaleza, forming the Ferrer-Urbano Santos Arch, and eastward increasing extension east of Fortaleza, leading to the formation of the Potiguar Basin. In this eastern portion, N-S extension was accompanied by E-W compression as the eastern tip of Brazil was pressed against Africa. The resulting stresses reactivated Precambrian ductile shear zones by transtensional movement, creating several inland half grabens including the Pendência, Orós, and Rio do Peixe grabens. During Alagoas (Aptian) time, rifting propagated westward along the Equatorial margin and eastward along the Benué trough, both of which became marine seaways. From Albian time on, right lateral transtensional movement created NW trending rhomb grabens along the Equatorial margin. From Campanian through Eocene time, this right lateral movement was repeatedly interrupted by $\mathrm{N}-\mathrm{S}$ compressional pulses which formed E-W trending folds and thrusts along the Equatorial margin and closed the seaway of the Benué trough. This compression may have been a distant reflex of the continental collision between Africa and Europe.
\end{abstract}

INTRODUÇÃo A separação da América do Sul e a África constituiu um assunto crucial para o desenvolvimento da moderna Tectônica de Placas. Devido à posição quase retangular das margens equatorial e oriental da América do Sul, que se encaixam perfeitamente nas reentrâncias correspondentes da África, o movimento relativo desses continentes é mais bem definido do que o de qualquer outro par de continentes em separação. Este fato, já ressaltado na teoria de deriva continental de Wegener (1929), ajudou a mantê-la viva no hemisfério sul (DuToit 1937) durante os 30 anos de sua morte aparente no hemisfério norte.

Ao se ressuscitar a Teoria de Deriva Continental numa forma geofisicamente correta como Tectônica de Placas, a separação desses continentes foi estudada com interesse renovado (LePichon \& Hayes 1971, Larson \& Ladd 1973). Estrella (1972) analisou o estágio rifte nas bacias da margem oriental do Brasil. Asmus \& Ponte (1973) e Campos et al. (1974) integraram as bacias da margem continental brasileira em relação à separação continental. Asmus \& Guazelli (1981) diferenciaram seqüências denominadas pré-rift-valley, rift-valley, proto-oceânica e oceânica. Gorini (1981) relacionou a margem equatorial do Brasil com as zonas de fratura equatoriais e com a margem meridional da Åfrica Ocidental.

A presença de estruturas compressionais nas bacias de Barreirinhas e do Ceará foi observada por Miura \& Barbosa (1972) e estudada em relação à transcorrência dextral ao longo da margem equatorial por Figueiredo (1982), Bacoccoli \& Aranha (comunicação verbal 1983), Piazza (comunicação verbal 1984), Azevedo et al. (1984), Zalán \& Warme (1985) e Azevedo (1986).

Com base em trabalhos geofísicos no Atlântico Sul próximo às plataformas continentais da África do Sul e da
Argentina, Rabinowitz \& LaBrecque (1979) sugeriram que, durante a primeira fase da separação, no Neocomiano e no Aptiano, o pólo da rotação relativa dos dois continentes se encontrava no hemisfério sul, próximo à cidade de São Luís (MA).

A criação de um grupo de pesquisas tectônicas pela gerência da Petrobrás para interpretar o grande volume de dados obtidos pela intensa exploração das bacias terrestres e da plataforma continental, juntamente com a disponibilidade de integrações regionais da geologia brasileira (Almeida et al. 1977, DNPM 1981, Neves 1983, Almeida \& Hasui 1984, Schobbenhaus et al. 1984, Cordani et al. 1984), abriu caminho para o estudo, em escala continental, da cinemática da separação. Szatmari et al. (1984, 1985a), Milani (1985), Lana (1985), Lana \& Milani (1986) e Milani et al. (1987) analisaram os efeitos que a rotação ao redor de um pólo contido dentro do continente causou sobre a margem oriental e definiram a microplaca do Nordeste Brasileiro, enquanto Szatmari et al. (1985b, 1985c), Françolin \& Szatmari $(1985,1987)$ e Zanotto \& Szatmari $(1985,1987)$ estudaram o mecanismo de separação para a margem equatorial do Brasil. Esses trabalhos envolveram estudos detalhados das falhas, tanto em seções sísmicas da Petrobrás, como no campo. Um trabalho paralelo (Miranda et al. 1986), usando sensoriamento remoto e dados de campo, e feito em cooperação com os autores deste trabalho, mostrou os efeitos da movimentação continental proposta por estes sobre o estruturamento fanerozóico do Pré-Cambriano aflorante nas cercanias das bacias de Barreirinhas e do Ceará. Resultados afins foram obtidos por estudos independentes fora da Petrobrás (Gama Jr. 1986).

$\mathrm{O}$ presente trabalho visa apresentar um modelo integrado da movimentação da América do Sul em relação à África,

* Petrobrás/Centro de Pesquisas e Desenvolvimento Leopoldo A. Miguez de Mello (Cenpes/Divex). Cidade Universitária, Quadra 7, Prédio 20, Ilha do Fundão, CEP 21910, Rio de Janeiro, RJ, Brasil

** Petrobrás/Debar/Dinter. Rua Interventor Mário Câmara, 2.783, CEP 59000, Natal, RN, Brasil

*** Petrobrás/Departamento de Exploração (Depex). Avenida Chile, 64, CEP 20000, Rio de Janeiro, RJ, Brasil 
coerente com as evidências obtidas na margem oriental e capaz de interpretar satisfatoriamente a cinemática das falhas principais ao longo da margem equatorial.

A FRAGMENTAÇÃO DOPANGEA O movimento contínuo e aleatório dos continentes ocasionalmente leva-os a se concentrarem num único hemisfério da Terra. Isso aconteceu pelo menos duas vezes durante a história terrestre: a primeira no Proterozóico e a segunda no fim do Paleozóico, sendo ambas as vezes acompanhadas por grandes orogenias entre os continentes em colisão. A colisão da América do Norte com o Gondwana no fim do Paleozóico formou as Montanhas Ouachita entre a América do Norte e a América do Sul e as Montanhas Apalachianas em sua continuação entre a América do Norte e a África, onde se fechou o Oceano Iapetus.

A formação do megacontinente Pangea por colisão de continentes no fim do Paleozóico fez com que temporariamente cessasse o movimento das placas que os carregaram. Esse movimento faz parte da convecção térmica do manto, de modo que seu término significou uma interrupção na dissipação do calor da Terra, que continuava sendo gerado pela desintegração de elementos radioativos em seu interior. Como resultado, acabou por se rachar a litosfera da Terra, tal como um motor cujo resfriamento por meio de convecção de fluidos ficara interrompido.

Usando uma projeção Mercator oblíqua (Fig. 1), LePichon \& Huchon (1984) demonstraram que as fraturas ao longo das quais o Pangea se desintegrou constituem dois sistemas, de direção $\mathrm{N}-\mathrm{NE}$ e W-NW em relação à posição atual da América do Sul, e que correspondem a um par de cisalhamento conjugado formando cerca de 45 graus com o limite entre Pangea e Pantalassa. Antes do reinício da subducção, e com ela, do resfriamento conveccional do manto, a direção perpendicular a esse limite era a do maior esforço compressivo, tornando-se, a seguir, a do menor esforço.

Com a renovada subducção das margens do Pangea, tornou-se possível o espalhamento de seus fragmentos continentais, que invadiram o domínio oceânico da Pantalassa, diminuindo-a para o atual Oceano Pacífico, enquanto novos oceanos se abriram entre os continentes em espalhamento (LePichon \& Huchon 1984).

A velocidade de separação desses novos continentes dependia inversamente da duração de sua união anterior. Aqueles que durante a maior parte do Paleozóico já estavam separados, unindo-se apenas durante as colisões no fim do Paleozóico, foram os primeiros a se separar: durante o Triássico por riftes e no Eojurássico por proto-oceanos que depositavam sal. Foi isso que sucedeu entre a América do Norte e América do Sul, entre a América do Norte e a África, e entre esta e a Europa.

Por outro lado, os continentes que se encontravam unidos durante todo o Paleozóico, como a América do Sul com a Âfrica, levaram mais tempo para se separar, formando-se entre eles o rifte apenas no Eocretáceo e o proto-oceano no Mesocretáceo.

No entanto, já a primeira fase da fragmentação do Pangea teve, ainda no Eomesozóico, alguns reflexos no futuro rifte entre a América do Sul e a África, especialmente em suas porções terminais. As espessas coberturas de basalto na Bacia de Karroo foram contemporâneas à separação entre as

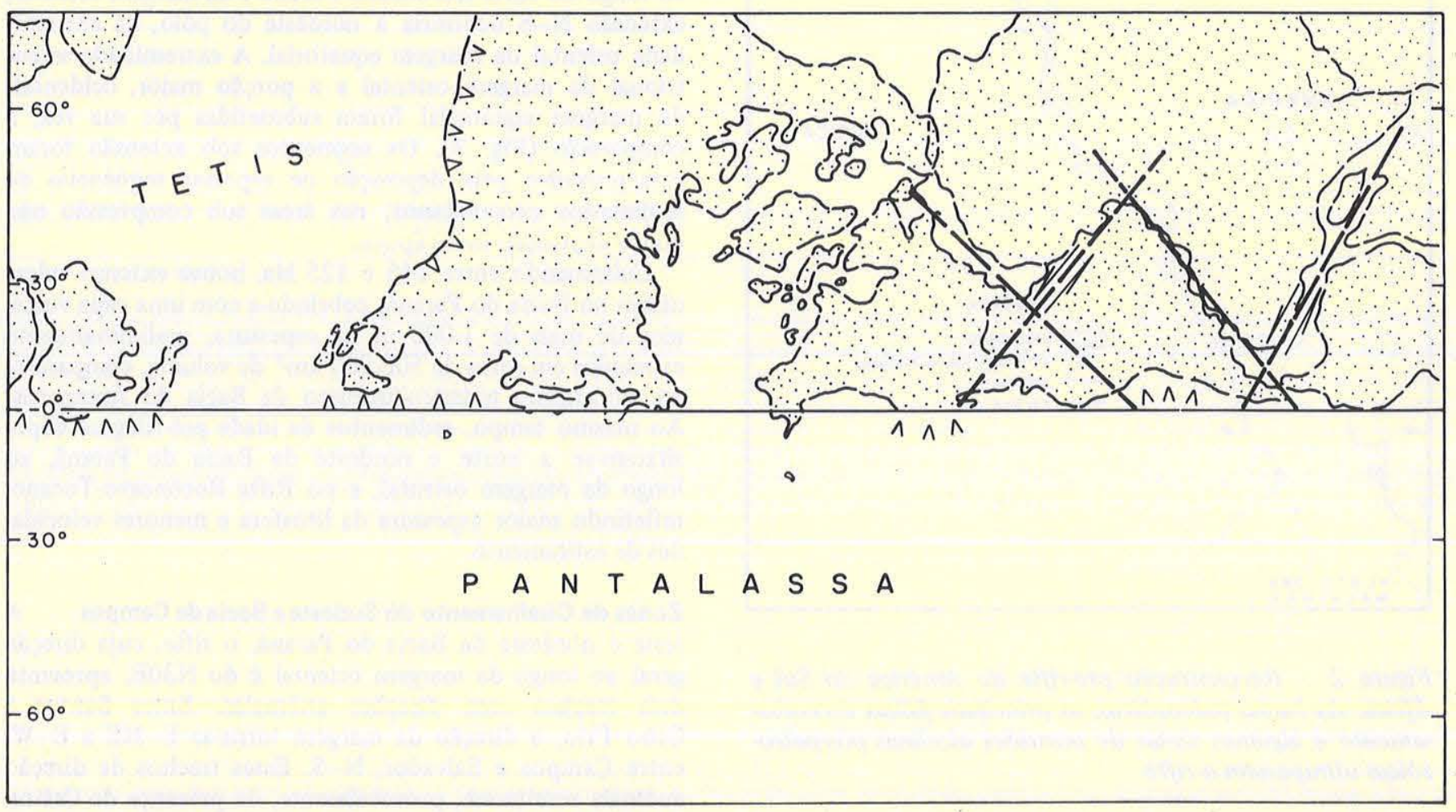

Figura 1 - Desintegração do Pangea no inicio do Mesozóico por fraturas conjugadas de cisalhamento. Projeção Mercator, com o limite entre o Pangea e Pantalassa servindo como o equador da projeção. As fraturas conjugadas que definem as margens Equatorial e Oriental da América do Sul encerram cerca de $45^{\circ}$ com esse limite (Modificado de Le Pichon \& Huchon 1984) 
porções oriental e ocidental do Gondwana, enquanto a separação entre as Américas do Norte e do Sul causou amplo vulcanismo na Bacia do Amazonas. Cerca de 500.000 $\mathrm{km}^{3}$ de magma basáltico, segundo estimativas preliminares, penetraram na seqüência sedimentar desta bacia, só não alcançando a superfície por causa da presença de camadas de sal paleozóicas (Szatmari et al. 1975). Simultaneamente, no Triássico e no Eojurássico (Thomaz Filho et al. 1974) houveram intrusões de diques de direção N-NW no Amapá e na Bacia de Cassiporé, indicando que o Escudo Güianense

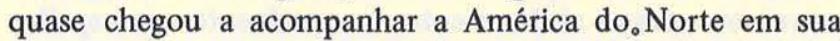
separação da América do Sul (Szatmari 1983). Houve nessa época também a intrusão de diques e a deposição de algumas centenas de metros de sedimentos na Bacia do Parnaíba, sem que essa tentativa de rifteamento se tivesse propagado mais para leste entre a América do Sul e a África.

\section{RIFTEAMENTO PRÉ-ALAGOAS NA MARGEM ORIEN-}

\section{TAL E NA BACIA POTIGUAR Reconstrução pré-rifte}

e rotação A figura 2 mostra a posição da América do Sul em relação à África antes do rifteamento neocomiano.

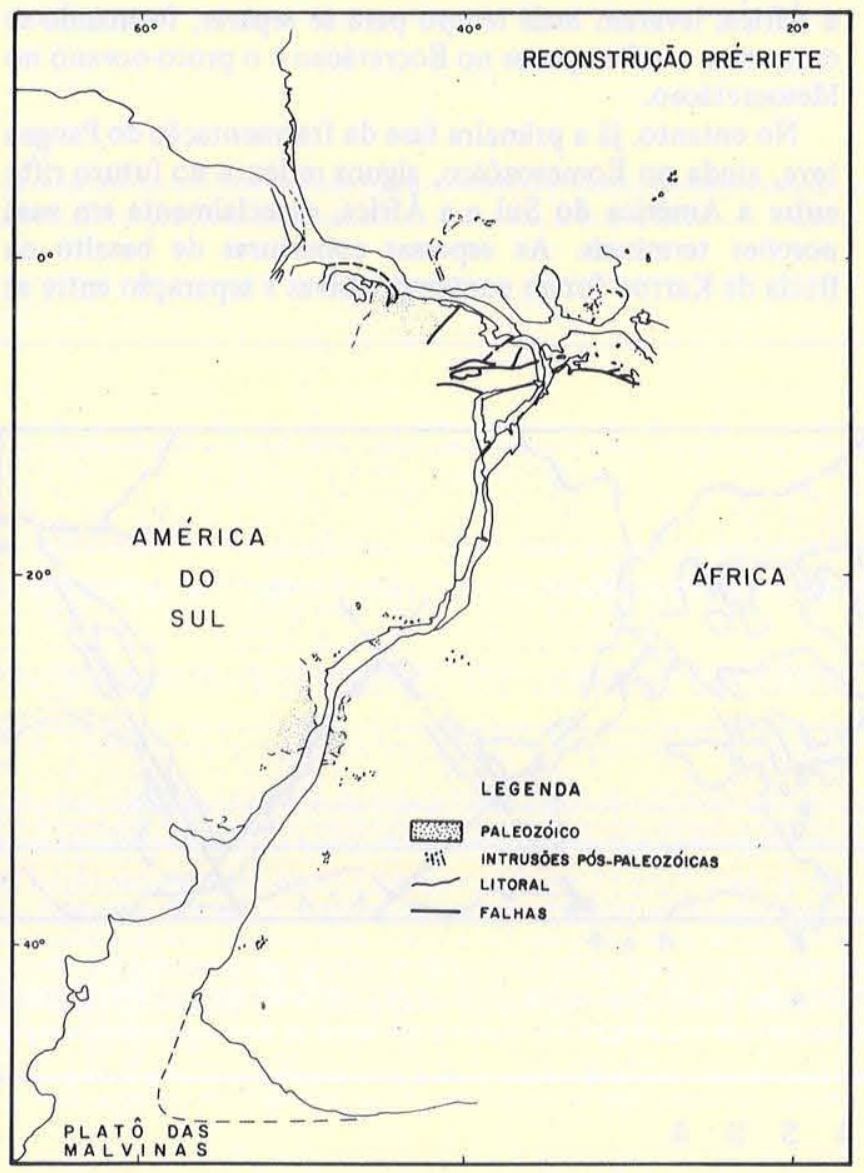

Figura 2 - Reconstrução pré-rifte da América do Sul e África. As bacias paleozóicas, as principais falhas do embasamento e algumas zonas de intrusões alcalinas pós-paleozóicas ultrapassam o rifte

A Bacia do Paraná e sua capa vulcânica estendem-se atualmente até um curto segmento da margem continental brasileira e, além deste, a um segmento correspondente da margem da África, refletindo o excelente ajuste entre os dois continentes. De forma semelhante, a bacia paleozóica do Parnaíba também continua no noroeste da África, sob a forma de camadas paleozóicas que margeiam a bacia proterozóica de Gana e Benin, e afloram na margem continental africana próximo a Acra. O soerguimento da África durante o Terciário, a julgar pela mais intensa atividade vulcânica relacionada a hot-spots, foi bem maior que o ocorrido no Brasil, de modo que a remoção da seqüência paleozóica naquele continente pode ter sido mais extensa que aqui.

Várias zonas de cisalhamento proterozóicas também passam, ao reconstruirmos o continente de Gondwana ocidental, do Brasil para a África, como, por exemplo, a Falha de Pernambuco, que continua na República dos Camarões (Gorini 1981) e a Falha de Sobral. O mesmo acontece com algumas zonas de intrusões alcalinas, ativas desde o Jurássico até o Terciário Inferior, uma das quais parece prolongar-se das proximidades da Bacia do Paraná até a parte central de Angola (Fig. 2).

Durante o Eocretáceo, a América do Sul, já separada da África por falhas conjugadas de cisalhamento (LePichon \& Huchon 1984), sofreu rotação horária em relação à África (Fig. 3). O pólo dessa rotação situava-se no nordeste brasileiro, como haviam sugerido Rabinowitz \& LaBrecque (1979), mas, em vez das proximidades de São Luís (MA), como propuseram esses autores, a análise da cinemática das falhas indica como locação mais provável desse pólo as proximidades de Lavras de Mangabeira, no Ceará, centro de uma região com deformação complexa.

A julgar pela distribuição dos sedimentos, a rotação diferenciou segmentos de extensão e compressão ao longo da margem continental. Havia extensão E-W a sul do pólo, ao longo do Rifte Recôncavo-Tucano e da margem oriental; extensão $\mathrm{N}-\mathrm{S}$ ocorreria a nordeste do pólo, na extremidade oriental da margem equatorial. A extremidade setentrional da margem oriental e a porção maior, ocidental, da margem equatorial foram submetidas por sua vez, a compressão (Fig. 3). Os segmentos sob extensão foram caracterizados pela deposição de espessas seqüências de sedimentos neocomianos; nas áreas sob compressão não houve deposição nesta época.

Culminando entre 145 e $125 \mathrm{Ma}$, houve extenso vulcanismo na Bacia do Paraná, cobrindo-a com uma capa vulcânica de mais de $1.000 \mathrm{~m}$ de espessura, preliminarmente estimados em cerca de $500.000 \mathrm{~km}^{3}$ de volume, comparável ao vulcanismo triássico-jurássico da Bacia do Amazonas. Ao mesmo tempo, sedimentos de idade pré-Alagoas depositaram-se a norte e nordeste da Bacia do Paraná, ao longo da margem oriental, e no Rifte Recôncavo-Tucano, refletindo maior espessura da litosfera e menores velocidades de estiramento.

Zonas de Cisalhamento do Sudeste e Bacia de Campos A leste e nordeste da Bacia do Paraná, o rifte, cuja direção geral ao longo da margem oriental é do N30E, apresentadois trechos com direções anômalas. Entre Santos e Cabo Frio, a direção da margem torna-se E-NE a E-W; entre Campos e Salvador, N-S. Esses trechos de direção anômala resultaram, provavelmente, da presença do Cráton do São Francisco, cuja crosta e litosfera espessa impediram a propagação do rifte.

Ao sul do Cráton do São Francisco, a parte central da Região de Dobramentos Sudeste é caracterizada por imen- 


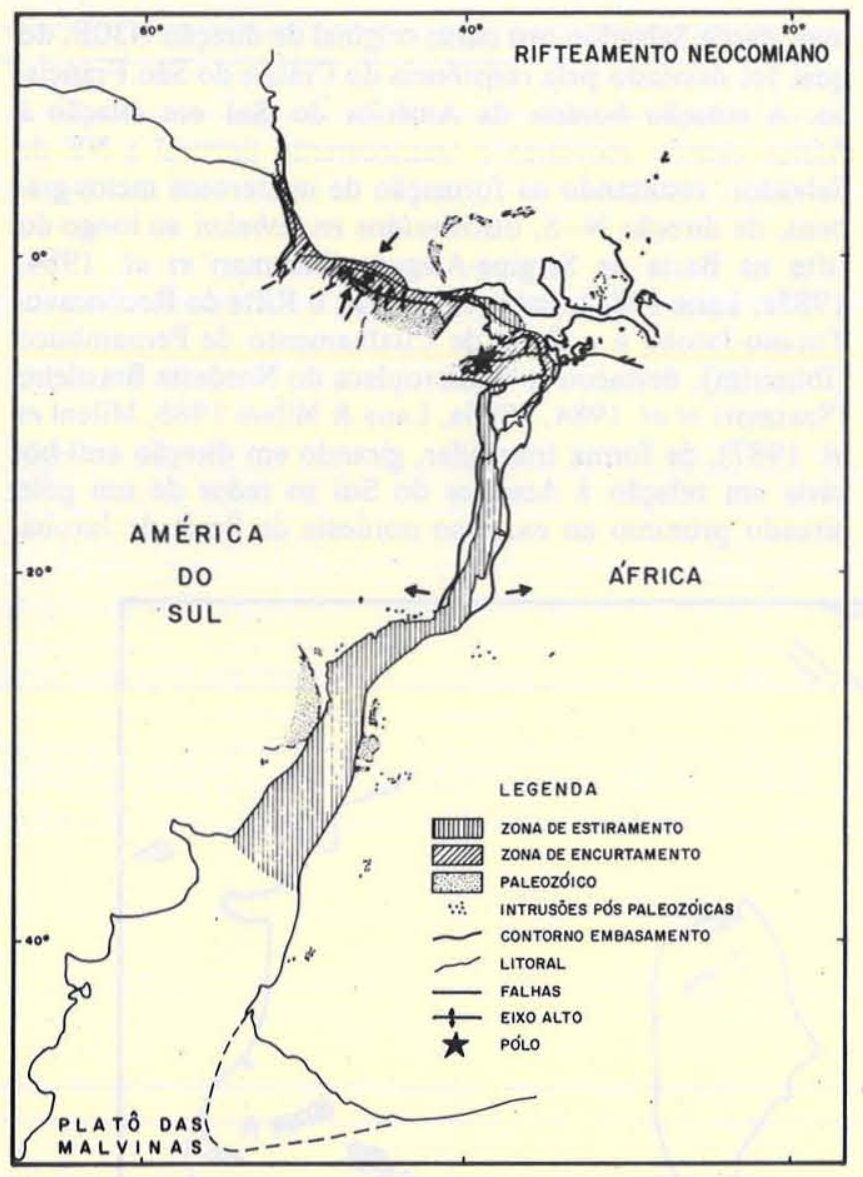

Figura 3 - Rifteamento neocomiano entre a América do Sul e a Africa por rotação relativa ao redor de um pólo situado no sul do Ceará. A sul do pólo abrem a margem oriental e o Rifte do Recôncavo-Tucano. A oeste do pólo, compressä̀ na margem equatorial resulta na formação de altos estruturais (Arco Ferrer-Urbano Santos). A nordeste e leste do pólo a distribuição de extensão e compressão é complexa

sas zonas de cisalhamento dúctil (Taxaquara, Cubatão, Além-Paraíba), em sua maioria de direção N70E (Hasui et al. 1984), que apresentam fortes indícios de movimento transcorrente, provavelmente resultante de manifestações finais de uma colisão continental oblíqua durante o Ciclo Brasiliano (Wernick \& Artur 1986). O conjunto dessas zonas de cisalhamento do sudoeste continua até a região de Campos. No segmento mais oriental, as falhas transcorrentes repetidamente se bifurcam, com um dos ramos continuando para ENE ou NE e o outro defletindo para norte (Fig. 4). Como o movimento dos blocos foi dextral na direção ENE-WSW, nas falhas de direção N-S o deslocamento passa de transcorrente para empurrão ou falha reversa, com correspondente diminuição do mergulho da falha.

Zonas de cisalhamento desse tipo cortam profundamente a crosta e provavelmente toda a litosfera, criando assim uma zona de fraqueza permanente e facilmente reativável. Admite-se que as zonas de cisalhamento do sudeste foram reativadas dentro da Bacia de Campos, durante o rifteamento do Eocretáceo, mas por transcorrência sinistral, inversa ao sentido do movimento proterozóico-eopaleozóico (Szatmari et al. 1984, 1985a). A África, situada a sudeste da zona de cisalhamento, deslocou-se para leste, e a América do Sul, situada a noroeste desta zona, para oeste. Como conseqüência dessa inversão do movimento transcorrente, houve uma inversão correspondente na ação das falhas mapeadas na Bacia de Campos, que formam uma perfeita réplica do segmento mais oriental da zona de cisalhamento que aflora em terra a NW de Campos. Fora da bacia, onde o movimento no Ciclo Brasiliano foi dextrógiro, quanto mais uma falha deflete para norte, tanto mais compressional ela fica, enquanto na Bacia de Campos, onde a transcorrência foi reativada como levógira durante o Eocretáceo, quanto mais uma falha deflete para norte, tanto mais extensional ela se torna (Fig. 4). Alguns dos campos mais ricos de petróleo encontram-se onde essas falhas de direção $\mathrm{N}-\mathrm{S}$, reativadas como extensionais, ramificam-se das de direção NE. A Bacia de Campos, como um todo, também se situa próximo a uma grande deflexão da margem continental, de ENE para NNE.

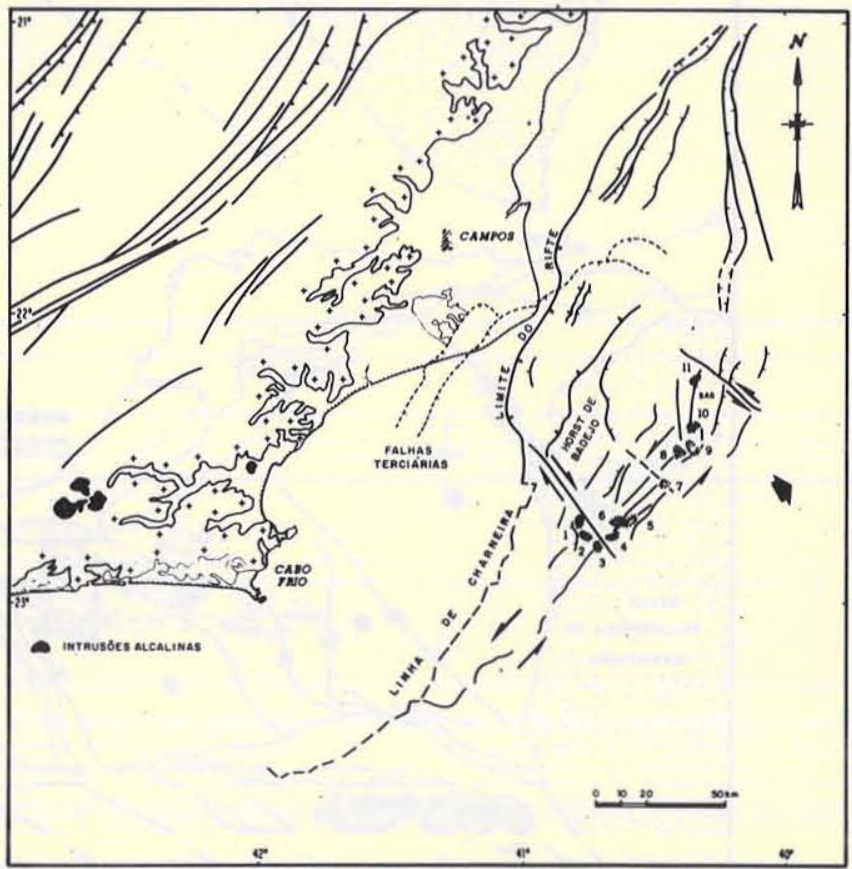

Figura 4 - Relacionamento entre as falhas da Bacia de Campos e as do embasamento aflorante (Modificado de DNPM 1:2.500.000 e Szatmari et al. 1985a). Campos de petróleo: 1. Badejo; 2. Linguado; 3. Pampo; 4. Bicudo; 5. Bonito; 6. Enchova; 7. Corvina; 8. Cherne; 9. Namorado; 10. Garoupa; 11. Carapeba. A seta indica movimento relativo da Africa durante a idade Alagoas

Microplaca do Nordeste Brasileiro A norte das zonas de Cisalhamento do Sudeste, o rifte passa a ter direção $\mathrm{N}-\mathrm{S}$, sempre margeando o Cráton do São Francisco e paralelizando seu estruturamento interno. Essa direção $\mathrm{N}-\mathrm{S}$ do rifte fica mantida até $500 \mathrm{~km}$ a norte de Salvador, formando a margem continental a sul desta cidade e o rifte abortado do Recôncavo-Tucano a norte. Entretanto, a direção geral N30E do rifte sul-atlântico foi imposta também a este trecho, manifestada pelas direções da Falha de Salvador, da Bacia do Recôncavo e das várias sub-bacias da Bacia de Tucano (Milani 1987). 
A direção $\mathrm{N}-\mathrm{S}$ do rifte termina no limite norte do Cráton do São Francisco, onde ocorre a Zona de Cisalhamento de Pernambuco, que é outra zona de cisalhamento de grande importância, de direção E-W, caracterizada por zonas miloníticas ramificadas (Santos 1971, Mello 1979). Como as zonas de cisalhamento do sudeste, aquelas do nordeste também foram, durante o Ciclo Brasiliano, sítios de deslocamento transcorrente dextral, provavelmente relacionados aos eventos finais de uma colisão continental oblíqua (Caby \& Arthaud 1986).

O Rifte Recôncavo-Tucano termina por deflexão brusca para ENE, margeando a Falha de Ibimirim e formando a estreita Bacia de Jatobá. Esse término brusco do rifte contra a Zona de Cisalhamento de Pernambuco forçou-o a reto- mar, desde Salvador, seu curso original de direção N30E, do qual foi desviado pela resistência do Cráton do São Francisco. A rotação horária da América do Sul em relação à África causou movimento transcorrente sinistral a NE de Salvador, resultando na formação de numerosos meios-grábens, de direção $\mathrm{N}-\mathrm{S}$, distribuídos en échelon ao longo do rifte na Bacia de Sergipe-Alagoas (Szatmari et al. 1984, 1985a, Lana 1985). Entre esta bacia, o Rifte do RecôncavoTucano-Jatobá e a Zona de Cisalhamento de Pernambuco (Ibimirim), destacou-se a Microplaca do Nordeste Brasileiro (Szatmari et al. 1984, 1985a, Lana \& Milani 1986, Milani et al. 1987), de forma triangular, girando em direção anti-horária em relação à América do Sul ao redor de um pólo situado próximo ao extremo nordeste da Bacia de Jatobá.

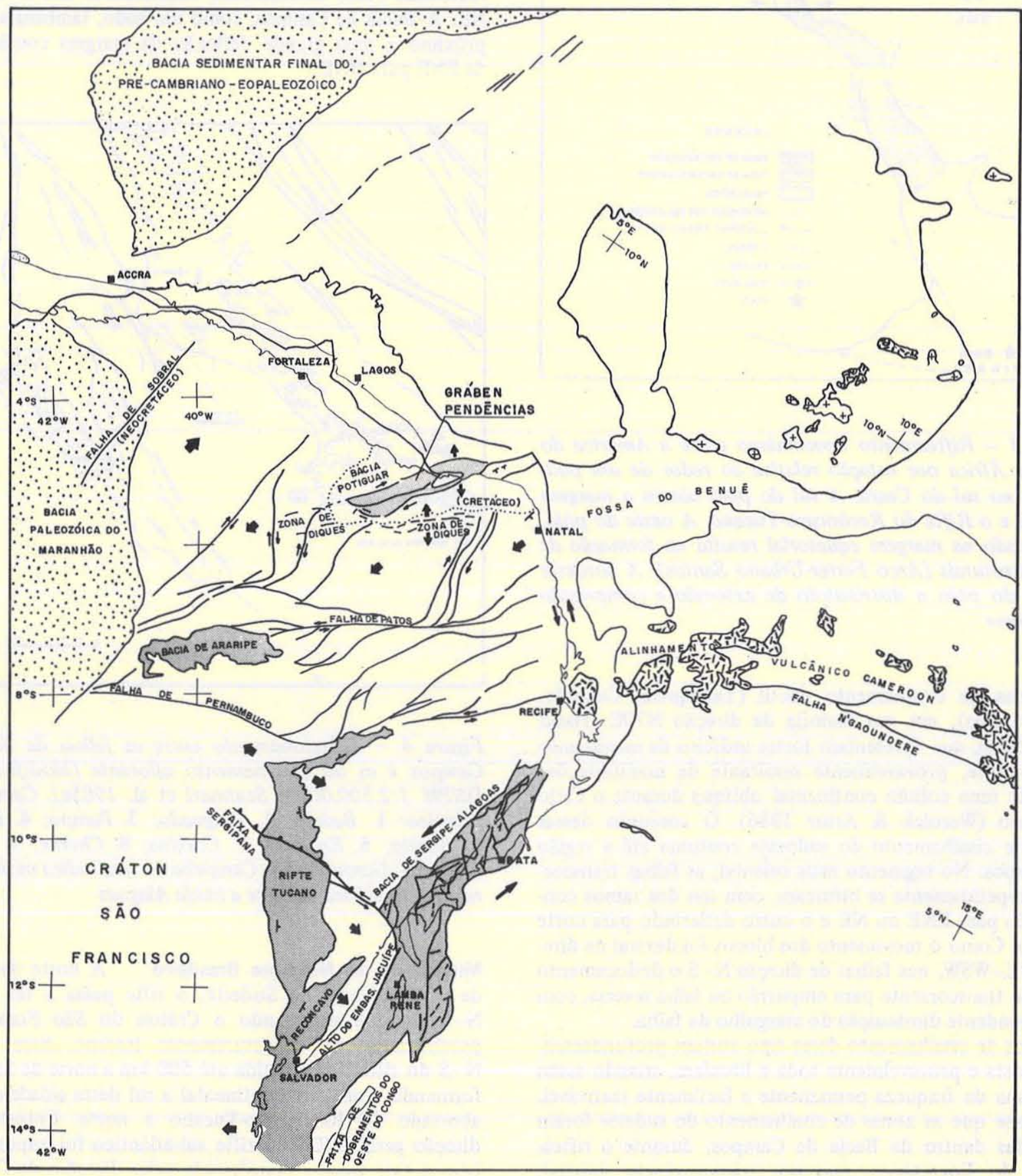

Figura 5 - Reconstrução pré-rifte do nordeste brasileiro e das regiões africanas adjacentes. As setas indicam movimento de blocos no Neocomiano (Fonte: Szatmari et al. 1985b) 
A Zona de Cisalhamento de Pernambuco divide em dois segmentos (Fig. 5) a porção setentrional da margem oriental, caracterizada por movimento transcorrente.

A sul do Recife, a transcorrência foi acompanhada por crescente afastamento dos dois continentes, permitindo a rotação da Microplaca do Nordeste Brasileiro, abrindo meio-grábens de direção $\mathrm{N}-\mathrm{S}$ na Bacia de Sergipe-Alagoas e fazendo com que, durante o tempo Alagoas, o rifte se propagasse cortando esses meio-grábens.

A norte da Zona de Cisalhamento de Pernambuco, pelo contrário, a transcorrência foi acompanhada por crescente compressão de direção $\mathrm{E}-\mathrm{W}$ entre os dois continentes, arredondando esse segmento mais setentrional da margem oriental e deslocando seus blocos para sudoeste por movimento transtensional dextral ao longo de zonas de cisalhamento proterozóicas-eopaleozóicas de direção NE. Uma dessas, a falha de Portalegre-Carnaubais, definiu o Gráben de Pendência na Bacia Potiguar (Françolin \& Szatmari 1985, 1987); outra, perto de João Câmara, apresenta sismicidade atual.

Essa compressão E-W na extremidade nordeste do Brasil teria provocado grandes empurrões, em vez de abertura de grábens, se não tivesse sido acompanhada por movimentos extensionais de igual ou maior intensidade em direção $\mathrm{N}-\mathrm{S}$. Mas a rotação horária do Brasil, dentro da reentrância da África, fez com que a extremidade oriental da margem equatorial se afastasse da Nigéria, a norte, formando riftes restritos ao segmento a leste de Fortaleza. A área a norte da Zona de Cisalhamento de Pernambuco e a leste de Fortaleza é, portanto, a única região do Brasil caracterizada, no Eocretáceo, por forte compressão de direção E-W acompanhada por forte extensão N-S (Françolin \& Szatmari 1985, 1987). Esse regime de esforços produziu, além do movimento transcorrente, um enxame de diques basálticos de idade neocomiana $(125 \mathrm{Ma})$ e de direção $\mathrm{E}-\mathrm{W}$ a sul do limite atual da Bacia Potiguar. Corpos ígneos básicos de mesma direção foram detectados também, por gravimetria, abaixo desta bacia, em continuidade, na reconstrução pré-rifte, com corpos básicos detectados da mesma forma abaixo dos sedimentos da Fossa do Benuê (Milani \& Latgé 1987). Simultaneamente com essa atividade vulcânica, abriu-se o Gráben de Pendência diagonalmente aos diques, por movimentos dextrógiros transtensionais ao longo de falhas reativadas de direção ENE.

A área afetada, durante o Neocomiano, por compressão E-W e extensão N-S, está limitada, a noroeste, pela Falha de Senador Pompeu, de direção N30E, paralela à margem oriental brasileira. A parte principal, ocidental, da margem equatorial sofreu compressão NNE-SSW no Neocomiano, simultaneamente à extensão quase $\mathrm{N}-\mathrm{S}$ de sua extremidade oriental e resultando da mesma rotação horária do continente sul-americano em relação à África (Figs. 3 e 5). Sugere-se que essa compressão tenha formado o Arco de FerrerUrbano Santos (Zanotto \& Szatmari 1985, 1987), soerguendo o embasamento cristalino. A Plataforma de Pará-Maranhão, também com embasamento soerguido, faz parte da mesma zona comprimida.

A compressão $\mathrm{N}-\mathrm{S}$, que afetou a margem equatorial, foi aliviada por deslocamento de fatias crustais para SW ao longo de falhas transcorrentes levógiras, paralelas à margem oriental e produzidas pelo mesmo evento cisalhante. Entre elas, a Falha de Sobral foi a mais importante, mas houve deslocamento na mesma direção também ao longo de uma falha que cortava a Bacia do Baixo Amazonas e ao longo da Falha de Pisco-Juruá, situada mais a oeste (Szatmari 1983).
RIFTEAMENTO DE IDADE ALAGOAS NA MARGEM EQUATORIAL E NA FOSSA DO BENUE Durante a idade Alagoas (que em parte coincide com o Aptiano), o rifte de direção $\mathrm{N} 30 \mathrm{E}$ da margem oriental se propagou desde Salvador até o Recife, cortando os meio-grábens de direção $\mathrm{N}-\mathrm{S}$ que se formaram durante o Neocomiano (Figs. $5 \mathrm{e}$ 6). O pólo da rotação horária da América do Sul em relação à África deslocou-se para oeste até próximo ao Oiapoque, de modo que o rifte se propagou até o extremo oeste da margem equatorial e se abriu um sistema de grábens que inclui os da Bacia de Marajó, de Bragança-Vizeu e de São Luís. Como resultado, a Plataforma de Pará-Maranhão parcialmente se separou do continente sul-americano.

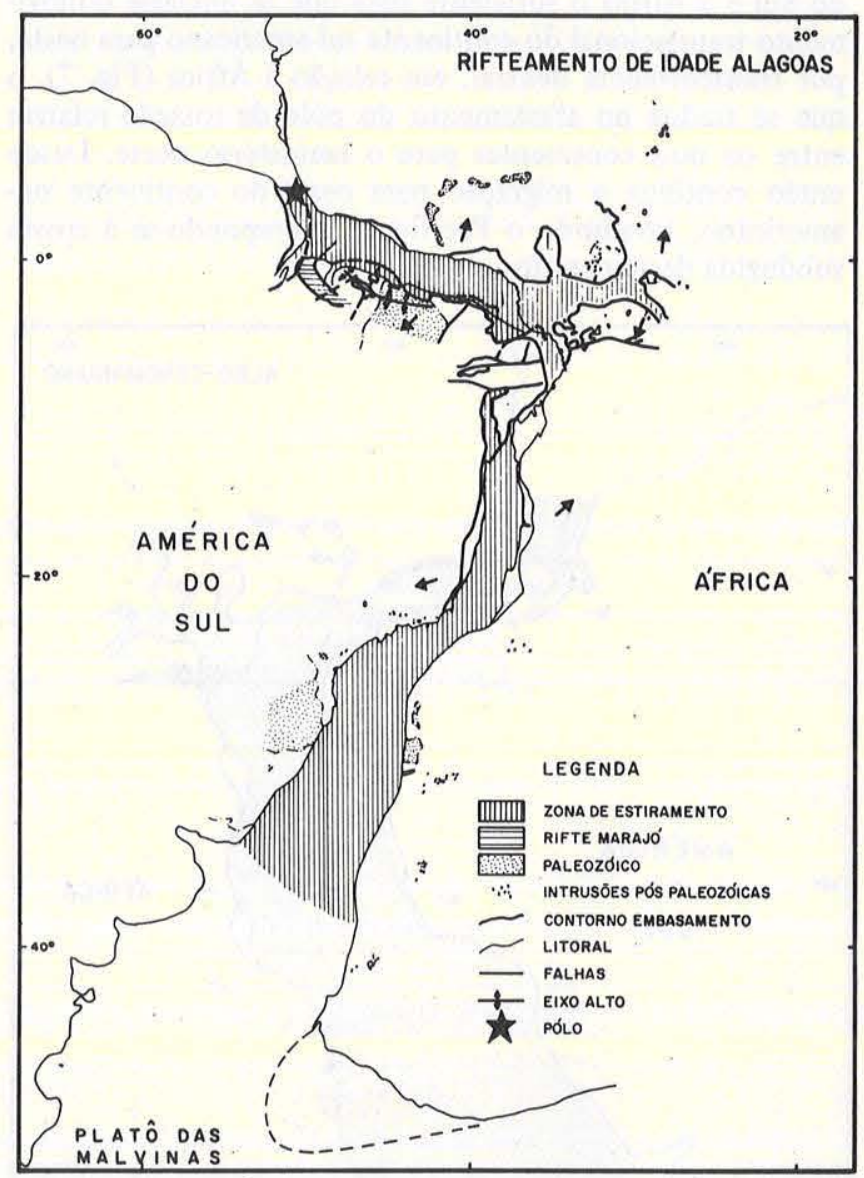

Figura 6 - Rifteamento de idade Alagoas entre a América do Sul e Africa. $O$ pólo de rotação relativa passa para as proximidades do Oiapoque. Ocorre estiramento generalizado ao longo da margem equatorial e, ao longo da continuação desta, na Fossa do Benuê. Abre-se o rifte de Marajó. $O$ Platô das Malvinas impede a entrada de águas oceânicas, permitindo a deposição de sal.

Ao mesmo tempo, propagou-se o rifte também para leste da Bacia Potiguar, separando a África setentrional e meridional por um sistema de grábens rômbicos ao longo da Fossa do Benuê (Popoff et al. 1983).

Ao longo da margem equatorial, o rifteamento se propagou em zigue-zague por segmentos alternadamente de direção E-W e N50W, cuja média é perpendicular ao eixo de maior estiramento. Sugere-se que esta predominância de riftes ligeiramente oblíquos em vez de perpendiculares a 
esse eixo reflete tanto a história estrutural anterior da região com a influência de uma fraca compressão $\mathrm{E}-\mathrm{W}$ no segmento da margem oriental situado entre o Recife e Natal. Em experiências com o modelador tectônico do Cenpes, riftes compostos de segmentos ligeiramente oblíquos foram obtidos ao se exercer uma ligeira compressão perpendicular à direção de extensão (Zanotto \& Szatmari 1985, 1987).

\section{MIGRAÇÃo CONTINENTAL PARA OESTE Desde a} transição aptiana-albiana, a extensão se generalizou ao longo da margem oriental, mesmo no segmento antes comprimido entre o Recife e Natal. Isso significa que o término do rifteamento ao longo da margem equatorial durante o Aptiano diminuiu a resistência da litosfera entre a América do Sul e a África o suficiente para que se iniciasse o movimento translacional do continente sul-americano para oeste, por transcorrência dextral, em relação à África (Fig. 7) o que se traduz no afastamento do pólo de rotação relativa entre os dois continentes para o hemisfério norte. Desde então continua a migração para oeste do continente sulamericano, invadindo o Pacífico e sobrepondo-se à crosta subduzida deste oceano.

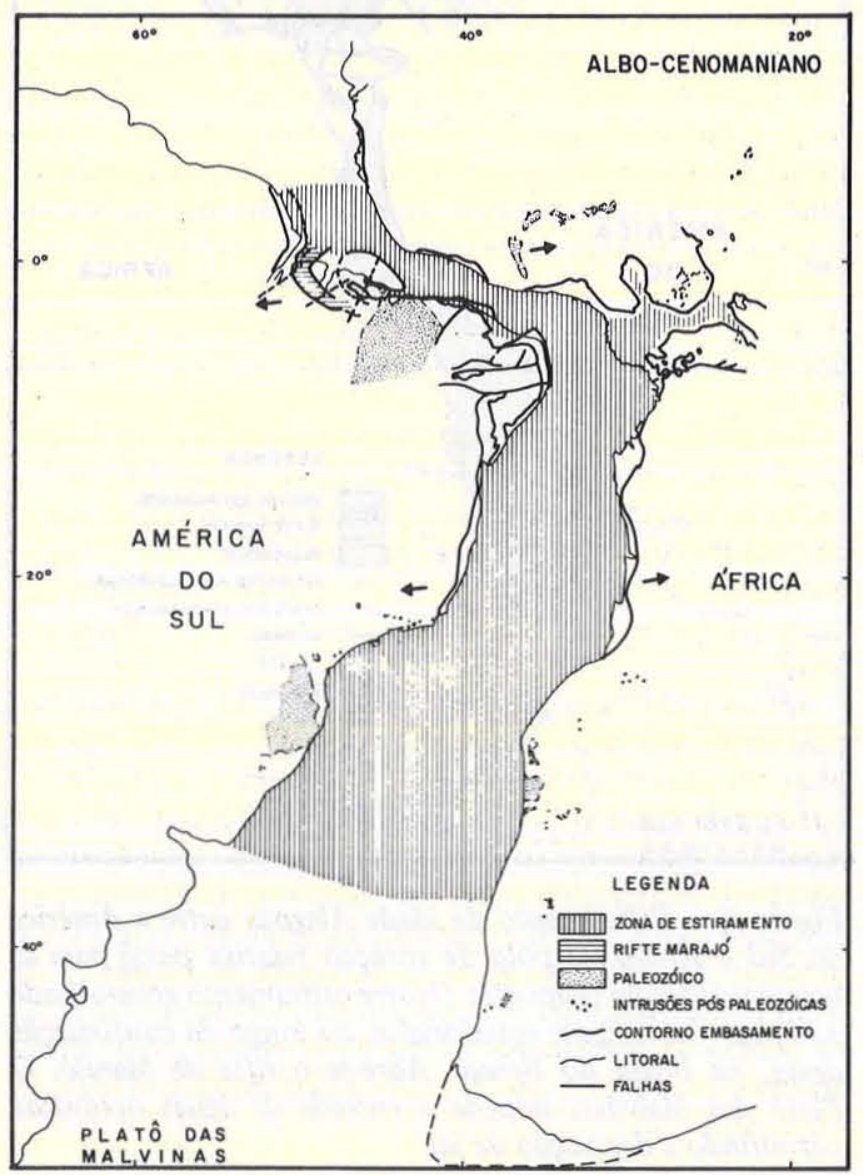

Figura 7 - Abertura do Oceano Atlântico durante o AlboCenomaniano. Movimento transcorrente divergente e dextrógiro predomina ao longo da margem equatorial

O movimento da América do Sul para oeste resultou em transcorrência dextrógira ao longo dos segmentos de direção $\mathrm{E}-\mathrm{W}$ do rifte da margem equatorial, fazendo com que estes recebessem poucos sedimentos durante o AlboCenomaniano enquanto ao longo dos segmentos de direção $\mathrm{N}-\mathrm{W}$ abriram-se grábens rômbicos, nos quais se deposita- ram mais de $2.000 \mathrm{~m}$ de sedimentos da mesma idade. Progrediu também a abertura do rifte na Fossa do Benuê na África. Desde o começo do Albiano havia comunicação entre as faunas sul e norte-atlânticas através do Atlântico Equatorial, e desde o fim do Albiano também entre as faunas do Atlântico Sul e do Oceano Tethys, através da Fossa do Benuê.

COMPRESSÃO NEOCRETÁCEA-EOTERCIÁRIA Desde o Coniaciano houve repetidos pulsos de compressão ao longo da margem equatorial e sua continuação oriental, a Fossa do Benuê (Fig. 8). Esses pulsos compressionais culminaram no fim do Neocretáceo, mas continuaram no Eoterciário. A esses movimentos, os autores atribuem o soerguimento e a erosão da seqüência paleozóica na extremidade nordeste da Bacia do Parnaíba, e o dobramento da Formação Humberto de Campos na Bacia de Barreirinhas. $\mathrm{O}$ eixo de compressão variava entre NW-SE (coerente com a transcorrência dextral ao longo das falhas de direção $\mathrm{E}-\mathrm{W}$ ) e $\mathrm{N}-\mathrm{S}$, esta última mais expressiva.

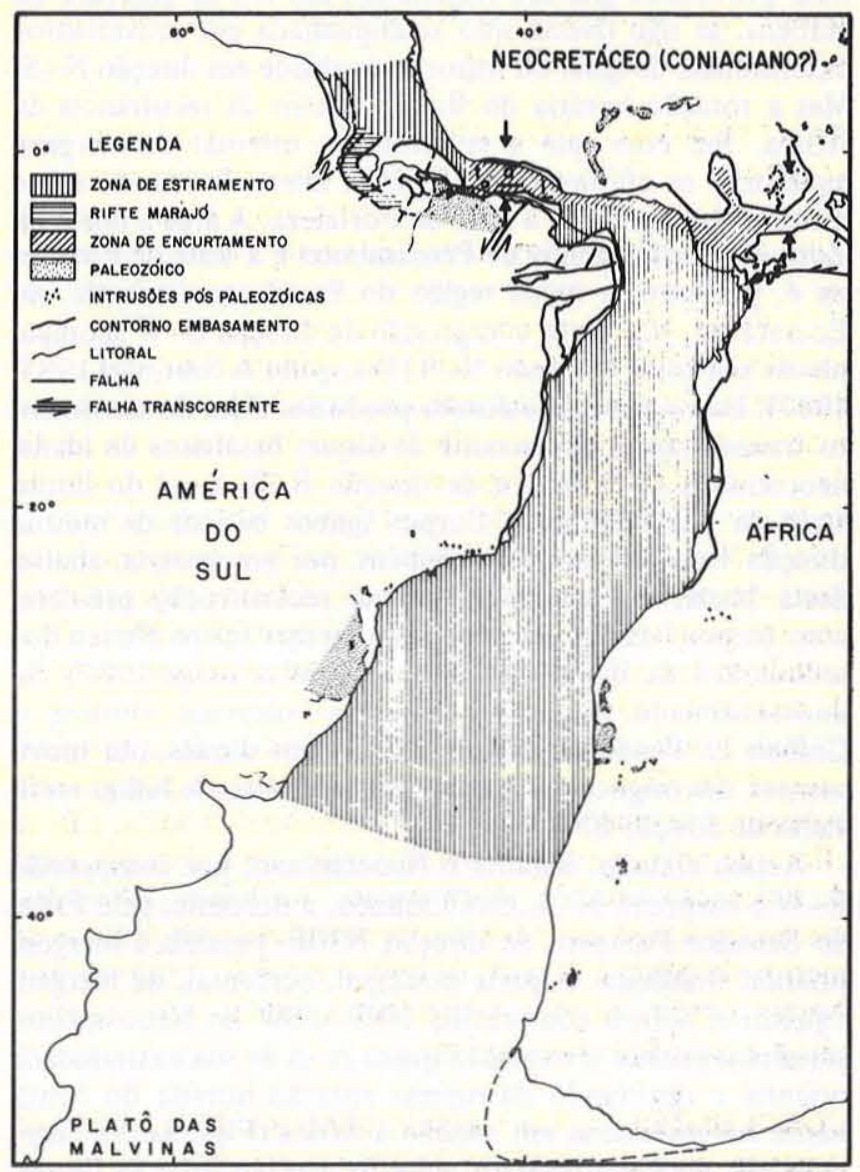

Figura 8 - Primeiro pulso de compressão $N-S$ no Neocretáceo (Coniaciano? ) ao longo da margem equatorial e sua continuação, a Fossa do Benuê. t, Braquianticlinal de Tutóia; a, Alto Atlântico; i, Falha de empurrão de Icaraí

Na plataforma do Ceará, o Alto Atlântico, de direção E-W e situado próximo ao limite sul da Zona de Fratura Romanche, contém rochas vulcânicas de idade eocênica. Ao longo de sua extensão, a oeste, ocorre, na Bacia de Barreirinhas, o Braquianticlínio de Tutóia (Fig. 8), em que o Terciário Superior se sobrepõe diretamente a sedimentos de 
idade Alagoas. A leste do Alto Atlântico, e da continuação da Falha de Sobral, formou-se a falha de empurrão de Icaraí, também de direção quase $\mathrm{E}-\mathrm{W}$, que mergulha 30 graus para norte e sobre a qual o deslocamento vertical para sul excede $1.000 \mathrm{~m}$. Essa falha se estende de Icaraí por mais de $60 \mathrm{~km}$ para N80E. A oeste de Icaraí, junta-se com a falha marginal do rifte, contra a qual a compressão arqueou as camadas. Dobras ocorrem também sobre a falha de empurrão a leste de Icaraí, especialmente nos trechos onde o mergulho desta aumenta.

$\mathrm{Na}$ Fossa do Benuê, dobramentos e empurrões são muito intensos no fim do Cretáceo, afetando a seqüência inteira do Albiano até o Turoniano nas sub-bacias do Baixo e do Médio Benuê e até o Maastrichtiano na do Alto Benuê (Popoff et al. 1983).

Os autores sugerem que os pulsos de compressão neocretáceos a eoterciários, durante os quais a transcorrência divergente ao longo das zonas de fratura equatoriais (Romanche, Chain, São Paulo) tornou-se convergente, resultaram da convergência entre a Europa e a África, que causou orogenias importantes na região mediterrânea, das quais os pulsos de compressão e transpressão equatoriais foram apenas um reflexo atenuado.

\section{REATIVAÇÃO PÓS-APTIANA DA FALHA DE} SOBRAL Esses pulsos de compressão, provenientes do norte, reativaram o movimento transcorrente ao longo da falha de Sobral, de direção N30E, paralela à margem oriental.

A Falha de Sobral alcança a margem equatorial na mesma direção onde o faz a falha de empurrão de Icaraí, de direção E-W. Próximo à margem na cidade de Santana de Acaraú, a Falha de Sobral aflora como uma zona milonítica de $1-2 \mathrm{~km}$ de largura, cujos milonitos em parte provêm de andesitos e conglomerados cambrianos. Acompanhando o lado NW da faixa milonitizada, arenitos e conglomerados siluro-devonianos da Formação Serra Grande estão colocados em posição íngrime (cerca de 70 graus para NW), diminuindo-se o mergulho para 20 a 30 graus a poucas centenas de metros da falha.

Mais a sudoeste, a Falha de Sobral forma a zona marginal sudeste da Bacia do Paranaíba, caracterizada por grandes espessuras sedimentares. Na parte sudoeste da bacia, a falha aflora de novo, cortando arenitos triássicos e albianos, estes da Formação Urucuia. Nesta região, Northfleet (1966) descreveu, ao longo da falha, cristas silicificadas de dezenas de metros de altura e dezenas de quilômetros de comprimento. Nessas cristas, nítidos estriamentos horizontais testemunham a reativação pós-Aptiana.

CONCLUSÓES Uma análise integrada da separação da América do Sul e a Africa permite interpretar a estrutura- ção e sedimentação ao longo da margem continental brasileira pela rotação diferencial de dois corpos não totalmente rígidos ao redor de um pólo que migrava durante o Cretáceo.

A separação iniciou-se no Permo-Triássico pela formação de dois sistemas conjugados de fraturas de cisalhamento dentro do Pangea (LePichon \& Huchon 1984). A separação da América do Sul e África foi retardada, em relação à da América do Norte e África, pela existência de uma litosfera espessa resultante da longa união do Gondwana durante o Paleozóico.

Durante o Triássico e o Jurássico, a intensa atividade vulcânica na Bacia do Amazonas e no Amapá refletia a tendência de o Escudo Güianense seguir a América do Norte em sua separação da América do Sul (Szatmari 1983).

Durante o Eocretáceo (pré-Alagoas), a América do Sul girava no sentido horário em relação à África ao redor de um pólo situado entre as bacias de Jatobá e de Potiguar, resultando em compressão $\mathrm{E}-\mathrm{W}$ e estiramento $\mathrm{N}-\mathrm{S}$ a leste, e em compressão NNE-SSW a oeste de Fortaleza (Szatmari et al. 1985b). O complexo sistema de falhas nordestinas (falhas de Pernambuco, Patos, Portalegre, Sobral etc.), foi reativado por movimentos transtensional (transcorrência divergente) e transpressional (transcorrência convergente). Tais falhas possivelmente se formaram ou haviam sido reativadas já durante uma colisão proterozóica (Caby \& Arthaud 1986). Os movimentos eocretáceos produziram o Gráben de Pendência na Bacia Potiguar, vários grábens interiores a sul deste (Orós, Rio do Peixe), e o Arco Ferrer-Urbano Santos. Simultaneamente destacou-se e girou em sentido anti-horário em relação à América do Sul, a Microplaca do Nordeste Brasileira (Szatmari et al. 1984, 1985a, Lana \& Milani 1986).

Durante o Alagoas, o continente girou em relação à África ao redor de um pólo situado próximo ao Oiapoque, causando a abertura de riftes na Bacia do Marajó, ao longo de toda a margem equatorial e na Fossa do Benuê. Simultaneamente, destacou-se em parte do continente sul-americano a Microplaca da Ilha de Santana, a leste do Rifte do Marajó.

Desde o Albiano, a América do Sul está se deslocando para oeste, por rotação em relação à África ao redor de um pólo situado no hemisfério setentrional. Essa deriva foi interrompida desde o Coniaciano até o Terciário Inferior por repetidos pulsos de compressão $\mathrm{N}-\mathrm{S}$, que resultaram da colisão da África com a Europa Meridional (Szatmari et al. 1985b, 1985c). Como resultado, surgiram estruturas compressivas de tendência geral E-W (falha de empurrão de Icaraí, Alto Atlântico com vulcanismo riolítico no Eoceno) na porção da margem equatorial ainda oposta pela margem africana próxima, e foi dobrada a seqüência cretácica da Fossa do Benuê.

\section{REFERENNCIAS BIBLIOGRAFICAS}

ALMEIDA, F.F.M. de; HASUI, Y.; BRITO NEVES, B.B. de; FUCK, R.A. - 1977 - Províncias estruturais brasileiras. In: SIMP. GEOL. NORDESTE, 8, Campina Grande. Atas... p. 363-391. (Versão em inglês. Earth Sci. Reviews, 1981, 17:1-29.

ALMEIDA; F.M. \& HASUI, Y. (coords.) - 1984 - O Pré-Cambriano do Brasil. São Paulo, Blücher, 378p.

ASMUS, H.E. \& PONTE, F.C. - 1973 - The Brazilian marginal basins. In: NAIRN, A.E.M. \& STEHLI, F.G. (eds.) The ocean basins and margins. New York, Plenum. p.87-133.

ASMUS, H.E. \& GUAZELLI, W. - 1981 - Descrição sumária das estruturas da margem continental brasileira e das áreas oceânicas e continentais adjacentes. In: PETROBRÁS. Estruturas $e$ tectonismo da margem continental brasileira, $e$ suas implicafões nos processos sedimentares e na avaliação do potencial de recursos minerais. Ro de Janeiro, Cenpes/Dintep. p.187-269. (Projeto Remac 9).

AZEVEDO, R.P. de; ROSSETTI, E.L.; NEPOMUCENO, F.F.; CAPUTO, M.V. - 1985 - Modelagem tectônica, origem e evolução da Bacia de Barreirinhas. In: SIMP. GEOL. AMAZÔNIA, 2, Belém, 1972. Anais... Belém, SBG. v. 1, p. 7-21. 
AZEVEDO, R.P. de - 1986 - Interpretação geodinâmica da evolução mesozóica da Bacia de Barreirinhas. In: CONGR. BRAS. GEOL., 34, Goiânia, 1986. Anais... Goiânia, SBG. v.3, p.1115-1130.

CABY, R. \& ARHAUD, M. H. - 1986 - Major Precambrian nappes of the Brazilian belt, Ceará, northeast Brazil. Geology, 14(10):871-874.

CAMPOS, C.W.M.; PONTE, F.C.; MIURA, K. - 1974 - Geology of the Brazilian continental margin. In: BURK, C.A. \& DRAKE, C.L. (eds.) Geology of continental margins. Berlin, Springer. p.447-461.

CORDANI, U.G.; BRITO NEVES, B.B.; FUCK, R.A.; PORTO, R.; THOMAZ FILHO, A.; CUNHA, F.M.B. - 1984 - Estudo preliminar da integração do Pré-Cambriano com os eventos tectônicos das bacias sedimentares brasileiras. Rio de Janeiro, Petrobrás, 70 p. (Ciências-Técnica-Petróleo 15).

DNPM-DEPARTAMENTO NACIONAL DE PRODUÇÃO MINERAL - 1981 - Mapa geológico do Brasil e da área oceânica adjacente incluindo depósitos minerais, escala $1: 2.500 .000$. Brasília, DNPM.

DuTOIT, B. - 1937 - Our wandering continents. Edinburgh, Oliver $\&$ Boyd.

ESTRELLA, G.O. - 1972 - O estágio rift na evolução das bacias marginais do leste brasileiro. In: CONGR. BRAS. GEOL., 26, Belém, 1972, Anais... Belém, SBG. v. 3, p. 29-34.

FIGUEIREDO, A.M.F.; TEIXEIRA, L.; AMORIM, J.; CARMINATTI, M. - 1982 - Projeto Barreirinhas, reavaliação da bacio cretácea; área terrestre e naritima. Petrobrás/Depex (Rel. int. Depex 103-239).

FRANÇOLIN, J.B.L. \& SZATMARI, P. - 1985 - Mecanismo de rifteamento da porção oriental da margem norte brasileira. In: CONGR. BRAS. PALEONT,, 9, Fortaleza, 1985. (inédito)

FRANÇOLIN, J.B.L. \& SZATMARI, P. - 1987 - Mecanismo de rifteamento na porção oriental da margem norte brasileira. Rev. Bras. Geoc., 17(2):195-207.

GAMA, Jr., E.C. \& ASSINE, M.L. - 1986 - Avaliação das possibilidades de petróleo nas áreas dos contratos de serviço 229 e 243, bacias do Araripe, Iguatu e Rio do Peixe. Belo Horizonte, Andrade Gutierrez Energia (Relatório).

GORINI, M.A. - 1981 - The tectonic fabric of the Equatorial Atlantic and adjoining continental margins. Gulf of Guinee to northeastern. Brazil. In: PETROBRAS, Estruturas e tectonismo da margem continental brasileira, e sua implicações nos processos sedimentares e na avaliação do potencial de recursos minerais. Rio de Janeiro. Cenpes/Dintep. p. 11-116 (Projeto Remac 9).

HASUI, Y.; FONSECA, M.J.G.; RAMALHO, R. - 1984 - A parte central da Região de Dobramentos Sudeste e o Maciço Mediano de Guaxupé. In: SCHOBBENHAUS, C. et al. coords., 1984, Geologia do Brasil. Brasília, DNPM. p. 307-328. Brasil. Brasília, DNPM. p. 307-328.

LANA, M.C. - 1985 - Rifteamento na Bacia de Sergipe-Alagoas, Brasil. Ouro Preto. 124p. (Dissertação de Mestrado, UFOP).

LANA, M.C. \& MILANI, E.J. - 1986 - A microplaca do Nordeste Brasileiro - um elemento dinâmico no rifteamento cretácico inferior. In: CONGR. BRAS. GEOL., 34, Goiânia 1986 Anais... Goiânia, SBG. v.3, p. 1131-1144.

LARSON, R.L. \& LADD, J.W. - 1973 - Evidences for the early opening of the South Atlantic in the Early Cretaceous. Nature, 246:209-212.

LE PICHON, X., \& HAYES, D.E. - 1971 - Marginal offsets, fracture zones and the early opening of the South Atlantic. $J$. Geophys. Res., 26:6283-6293.

LE PICHON, X. \& HUCHON, P. - 1984 - Geoid, Pangea and convection. Earth Planet. Sci. Lett., 67(1):123-135.

MELLO, A.A. de - 1979 - Características geológicas e metalotectônicas dos cinturöes móveis do Nordeste Oriental. Recife, CPRM (Publ. esp.).

MILANI, E.J. - 1985 - Tectônica cisalhante na evolução do Rift do Recôncavo-Tucano-Jatobá. Rev. Bras. Geoc., 15(4):287-292.

MILANI, E.J. - 1987 - Aspectos da evolução tectônica das bacias do Recôncavo e Tucano Sul, Bahia, Brasil. (Dissertação de Mestrado UFOP 1985). Petrobrás. 34p. (Ciência-Técnica-Petróleo 18).

MILANI, E.J.; LANA, M.C.; SZATMARI, P. - 1987 - Mesozoic rift basins around the NE-Brazilian microplate. In: MANSPEIZER, W. (ed.), Triassic-Jurassic rifting and the opening of the Atlantic Ocean. s.1. Elsevier.
MILANI, E.J. \& LATGÉ, M.A.L. - 1987 - Modelagem gravimétrica da porção terrestre da Bacia Potiguar e suas implicações geotectônicas. Bol Geoc. Petrobrás 1(1) (no prelo).

MIRANDA, F.P. de \& LIU, C.C. - 1986 - Análise estrutural e tectônica do Pré-Cambriano adjacente às bacias de Barreirinhas e do Ceará, através de dados de sensores remotos. Petrobrás (Relatório Interno).

MIURA, K. \& BARBOSA, J.C. - 1972 - Geologia da plataforma continental do Maranhão-Piauí, Ceará e Rio Grande do Norte. In: CONGR. BRAS. GEOL., 26, Belém, 1972. Anais... Pará, SBG. v.2, p.57-66.

NORTHFLEET, A. \& NEVES,S.B. - 1966 - Semidetalhe da região sudoeste de Alto Parnaiba. Belém, Petrobrás/Renor, 70 p. (Relatório Interno 130-2486).

POPOFF, M.; BENKHELIL, J.; SIMON, B.; MOTTE, J.J. - 1983 Approche géodynamique du Fossé de la Bénoué (NE Nigeria) à partir des donnés de terrain et de télédétection. In: POPOFF, M. \& TIERCELIN, J.-J., eds., Rifts et fossés anciens. Bull. Centres Rech. Explor.-Prod. Elf-Aquitaine, 7(1):323-337.

RABINOWITZ, P.D. \& LABRECQUE, V. - 1979 - The Mesozoic South Atlantic Ocean and evolution of its continental margin. J. Geophys. Res., 84 :(B11):5973-6002.

SANTOS, E.J. - 1971 - As feições estruturais da falha ArcoverdePernambuco e o mecanismo de falhamento da "Zona transversal". Rio de Janeiro. Rev. Min. Met., 53(313):35-40.

SCHOBBENHAUS, C.; CAMPOS, D.A.; DERZE. R.G.; ASMUS, H.E. (coords.) - 1984 - Geologia do Brasil. Brasília, DNPM. $501 \mathrm{p}$.

SZATMARI, P. - 1983 - Amazon rift and Pisco-Juruá fault; their relation to the separation of North America from Gondwana. Geology, $11: 300-304$.

SZATMARI, P.; CARVALHO, R.S.; SIMÕES, I.A. - 1975 - Evaporitos da Bacia do Amazonas. Rio de Janeiro, Petrobrás. (Rela*. tório Interno).

SZATMARI, P.; CONCEIÇÃO, J.C.J.; LANA, M.C.; MILANI, E.J.; LOBO, A.O, - 1984 - Mecanismo tectônico do rifteamento sul-atlântico. In: CONGR. BRAS. GEOL.,33, Rio de Janeiro 1984. Anais... Rio de Janeiro, SBG. v. 4, p. 1589-1601.

SZATMARI, P.; MILANI, E.J.; LANA, M.C.; CONCEIÇÃO, J.C.J.; LOBO, A.P. - 1985a - How South Atlantic rifting affects Brazilian oil reserve distribution. Oil \& Gas J., 83:107-113.

SZATMARI, P.; ZANOTTO, O.; FRANÇOLIN, J.; WOLFF, S. $1985 \mathrm{~b}$ - Rifting and early tectonic evolution of the Equatorial Atlantic. In: Geol. Soc. America 98th Annual Meeting, Orlando, Flórida, 1985. Abstracts with programs., p. 731.

SZATMARI, P.; FRANÇOLIN, J.; ZANOTTO, O. WOLFF, S. 1985 c - Rifteamento na Margem Equatorial do Brasil. In CONGR. BRAS. PALEONT., 9, Fortaleza, 1985. Boletim de resumos... Fortaleza, SBP.p. 91.

THOMAZ FILHO, A.; CORDANI, U.G.; MARINO, O. - 1974 Idades K-Ar de rochas basálticas da Bacia Amazônica e sua significação tectônica regional. In: CONGR. BRAS. GEOL., 28, Porto ALegre, 1974. Anais... Porto Alegre, SBG. v. 6, p 273-278.

WEGENER, A. - 1929 - Die Entstehung der Kontinente und Ozeane, 4 ed. Berlin, Vieweg $\&$ Sohn.

WERNICK, E. \& ARTUR, A.C. - 1986 - Interpretação de algumas feições geotectônicas do embasamento do Estado de São Paulo e áreas vizinhas: o modelo de colisão continental. In: CONGR. BRAS. GEOL., 34, Goiânia 1986. Anais... Goiânia, SBG. v. 3 p. $1285-1295$

ZALÂN, P.J. \& WARME; J.E. - 1985 - Tectonics and sedimentation of the Piaui-Camocim sub-basin, offshore northeastern Brazil. Rio de Janeiro, Petrobrás. 71 p. (CiênciaTécnica - Petróleo 17).

ZANOTTO, O. \& SZATMARI, P. - 1985 - Mecanismo de rifteamento da porção ocidental da margem norte brasileira. In: CONGR. BRAS. PALEONT., 9, Fortaleza. Boletim de resumos, p. 92.

ZANOTTO, O. \& SZATMARI, P. - 1987 - Mecanismo de rifteamento da porção ocidental da Margem Equatorial. Rev. Bras. Geoc., 17(2): 189-195. 